\title{
A MENTALIDADE ADMINISTRATIVA
}

CHARLES E. SUMMER JR.

\begin{abstract}
"Tendo em vista que por "boa" administração se entende aquêle comportamento que é objetivamente adequado aos seus fins [..] uma teoria das decisóes administnativas, terá; forçosamente, de preocupar-se de certa maneira com os aspectos racionais da escolha." - HERBERT SIMON.
\end{abstract}

- A maneira de pensar dos administradores de emprêsas pode ser caracterizada por qualidades e atitudes bem definidas, a exemplo do que ocorre com cientistas, advogados e outros profissionais?

- No que se assemelha a mentalidade administrativa à mentalidade científica ou profissional, ao lidar com fatos, números, teorias, coerência interna, mudanças, riscos e outras questões?

- No que difere a mentalidade administrativa das qualidades intelectuais que usualmente associamos aos médicos, advogados ou cientistas, ou quais as limitações dessa mentalidade?

- Qual o significado de tais semelhanças e diferenças para os homens de negócio e para os professôres de administração?

Encontramos de maneira clara na filosofia das ciências, artes e profissões, dados sôbre as qualidades da "menta-

Charles E. Summer JR. - Professor-Adjunto de Administração da Columbia University.

Nota da Redaçãc: Traduzido do original publicado na Harvard Business Review, janeiro/fevereiro de 1959 , por OLINDA V. MALMEGRIN, e reproduzido sob autorização. 
lidade científica", da "mentalidade criadora", da "mentalidade técnica, legal ou jurisprudencial". O mesmo não se dá, contudo, com referência à "mentalidade administrativa". Todavia, os homens que dirigem assuntos mundiais na indústria, no govêrno e nos serviços militares não são cientistas, artistas ou médicos. Destarte, pelo fracasso em estabelecer com alguma clareza as qualidades da "mentalidade administrativa", estaremos negando, tanto aos administradores individualmente, como à sociedade, vantagens positivas de ordem prática.

Enquanto outros enumeram as nobres qualidades da "mentalidade científica ou artística", o administrador profissional permanece à margem, não se considerando que a tomada de decisões administrativas pode apresentar-se complexa e intelectualmente difícil. Ao contrário do que ocorre nas demais profissões, há pouco reconhecimento pelos padrões que estimulam a competição na administração, sobrecarregando os esforços de treinamento de homens em tal campo. Ademais, as escolas de administração não apresentam aquêle conceito claro e equilibrado de objetivos que têm sido de grande valor para as escolas profissionais em geral.

Friso que não estou escrevendo sôbre habilidade, nem sôbre aptidões para formular decisões. Qualquer pessoa mesmo um novelista - reconhece que um bom administrador as possui. Estou, na verdade, principalmente interessado nas qualidades comuns de pensamento, nas atitudes, inclinações, predisposições, em suma, nos padrões de raciocínio que nos permitem caracterizar o administrador e predizer, se não como resolverá um problema, pelo menos como se portará na sua condução.

Para os propósitos que tenho estabelecidos, não é necessário definir tôdas as facêtas da "mentalidade profissional". Basta que admitamos ser o profissional um homem que utiliza os seus conhecimentos e das demais pessoas para obter resultados no mundo da ação real. Empenha-se na compreensão do ambiente ou da ordem natural, prevendo o que ocorrerá durante sua atuação e, em muitos casos, 
controlando tais ocorrências. Essa orientação para ação e resultados, e, para problemas de resolução da ação, que identifica as qualidades intelectuais de um profissional.

A questão de saber se a administração está ou não se tornando uma profissão, fica também colocada fora dos propósitos dêste artigo. E evidente, todavia, que se qualidades mentais semelhantes às aqui apresentadas forem aperfeiçoadas e aceitas como padrões, a administração estará muito mais próxima do status de profissão. Não será, porém, igual a nenhuma das profissões que conhecemos atualmente. A mentalidade administrativa está desenvolvendo muitas semelhanças com as mentalidades científica, técnica, médica e legal, mas apresenta também algumas diferenças. Está percorrendo caminho próprio, trabalhando numa direção independente. Isto é óbvio e deveria mesmo ocorrer; mas, o fato de apresentar nesta evclução um padrão desconhecido, explica porque tantas pessoas demoram em reconhecer a nova dimensão intelectual da administração.

Último lembrete: nesta discussão, ater-nos-emos exclusivamente às qualidades intelectuais do administrador. Apesar de serem de vital importância, deve-se, todavia, lembrar que outros atributos são também importantes: qualidades morais, estéticas e criativas - ou conhecimento e sabedoria advindos da experiência. Em verdade, algumas vêzes, essas qualidades não intelectuais podem ser bem mais importantes que as primeiras, seja do ponto de vista da emprêsa, ou da sociedade.

\section{ATRIBUTOS EMPÍRICOS}

Os atributos empíricos, intrínsecos e extrínsecos da mentalidade administrativa não constituem novidade. Porém, apresentam-se combinados de maneira diferente, e a êles é atribuída uma ênfase distinta da vigente na mentalidade médica ou técnic?.

O fato mais notório é que o administrador não conduz nenhum tipo particular de raciocínio empírico a extremos. 
Aqui, como em qualquer outro ponto dessa discussão, veremos que não existe preponderância de uma única atitude ou predisposição. Cada qual parece ser seguida com moderação, enfatizando a "integração" — um modo de pensar global, ao invés de repartido entre ingredientes individuais.

\section{Atitude Factual}

Alfred North Whitehead, grande filósofo e matemático, diz-nos que os cientistas sempre se limitaram à observação e à experimentação. ${ }^{1}$

A insistência de GaLILEo sôbre "fatos irredutíveis e imutáveis" levou a um descrédito do raciocínio, a ponto de, ainda hoje, existir entre alguns cientistas a impressão de que são "melhores" aquêles cujos métodos envolvem uma observação paciente dos fatos através da experiência ou de análises da experiência passada, em detrimento daqueles cujos métodos dependem essencialmente da razão e da lógica.

Êsse primeiro atributo empírico, que pode ser denominado atitude factual, é particularmente válido no campo da ação administrativa, onde o administrador tem que provocar ou controlar eventos específicos num contexto problemático. E péssimo que conclusões apressadas ou especulações imaginativas produzam decisões em desacôrdo com o mundo real de problemas e fatos.

A atitude factual é recorrente nos anais da administração. Por exemplo, quando a "General Motors" decidiu pela primeira vez entrar no ramo de motores Diesel, a administração recolheu grande número de fatos sôbre qual tipo de locomotiva de pequeno porte seria necessário e quais os passos para projetar, produzir e vender tal produto. Passou-se então a um procedimento metódico, baseando-se as ações nas evidências obtidas. Atualmente, o

1) Science and the Modern World, Nova Iorque: New American Library, 1948, págs. 9 e 17. 
cuidadoso planejamento a longo prazo de várias companhias atesta a importância da atitude factual. ${ }^{2}$

Em oposição encontramos vários exemplos de resultados insatisfatórios quando os fatos não são reunidos com muito cuidado antes da tomada da decisão. Por exemplo, uma série de estudos mostra que a razão primordial do fracasso de novos negócios é a especulação otimista de seus proprietários, que negligenciam a atitude factual com respeito à previsão das vendas, problemas operacionais, necessidades de capital etc..

Entretanto, a atitude factual pode conduzir a exageras. Se o administrador estiver preocupado em excesso com a necessidade de coletar "todos" os dados, poderá falhar em dcis aspectos: 1) em muitas decisões os fatcs referentes a um problema não podem ser conhecidos; 2) mesmo que se conheçam as várias espécies de fatos necessários, pode não haver tempo suficiente para sua obtenção.

Portanto, é necessária uma forma modificada da atitude factual, que diga, com efeito: "Ser paciente e querer obter os fatos, relutar quanto a conclusões apressadas, mas não hesitar em aplicat o raciocínio e o julgamento quando necessário, se a falta de fatos ou de tempo impedirem inteiramente a pesquisa de um problema."

A êsse respeito, a mentalidade administrativa não difere da mentalidade médica ou legal. Às vêzes, o médico é obrigado a tomar decisões rápidas, o advogado tem de aconselhar seu cliente antes que uma questão seja solucionada pelo tribunal. Todavia, uma atitude factual modificada seria irrelevante para um engenheiro ou pesquisador químico. Em outras palavras, temos aqui a primeira de uma série de semelhanças e contrastes entre a administração e as demais profissões.

2) Para documentação da experiência de várias ccmpanhias, veja-se Long-Range Planning for Management, editado por DAvid W. EwInG, Nova Iorque: Harper and Brothers, 1958. 


\section{Atitude Quantitativa}

O segundo atributo empírico pode ser chamado de atitude quantitativa. Os filósofos da ciência dizem-nos que os cientistas contam com um "pré-juízo", inato e distinto, para selecionar, dentro do ambiente, apenas aquêles fatos que podem ser mensurados. Um escritor salientou: "A conviç̧ão mais profunda de KEPLER era de que a natureza é essencialmente matemática, e tôda sua vida científica foi um esfôrço para descobrir as harmonias matemáticas da natureza. Também GALILEO não tinha dúvidas de que a matemática é uma das chaves verdadeiras dos fenômenos naturais." 3 $O$ fato de que essa preferência existe marcadamente, ainda hoje, é atestado pelos biólogos, físicos, antropólogos e outros.

$A$ atitude quantitativa satisfaz duas importantes necessidades do cientista: ajuda-o a ser objetivo e capacita-o a "provar" suas relações ou leis. Por exemplo, o que acontecerá a $x$ unidades da variável $y$ se a variável $b$ se transforma por $z$ unidades.

Essa predisposição matemática também pode ser valiosa para o administrador, conduzindo a formas mais eficazes de realizações. $O$ orçamento é um exemplo, uma vez que aqui estão envolvidos os problemas de custo-padrão e indices financeiros. A pesquisa operacional, os computadores digitais, a teoria das probabilidades e dos jogos, a teoria de sistemas, a automação e as ciências sociais, como a antropologia aplicada, têm aumentado as possibilidades de proceder cientificamente no sentido de medir as consequiências das decisões administrativas.

Esforços para quantificar complexos problemas administrativos têm sido tão freqüentemente bem sucedidos que quase todos os homens de negócio estão familiarizados pelo mencs com alguns dêles. Exemplificando:

3) J. W. N. Sultrvan, The Limitations of Science, Nova Iorque: New American Library, 1949, pág. 128. 
- O trabalho realizado na indústria química para programar complexos fluxos de subprodutos por meio de equações lineares.

- Os esforços de Thomas Malone, um meteorologista da "The Travelers Insurance Companies", e dos grupos da indústria petrolífera, para mostrar o que a quantificação pode fazer quando aplicada a contrôle de estoques de combustíveis à programação do refino, aos embarques de subprodutos e aos problemas de orçamento de capital.

A maioria dos homens de negócio tem tido ensejo de aprender o que pode ocorrer se a administração não tiver uma predisposição quantitativa - casos como o do nôvo dono de um grande jornal do meio-oeste quando descobriu que seu antecessor deixara de obter lucro durante 15 anos com anúncios, simplesmente porque "detestava cifras" e não separava, de maneira quantitativa, a parte de anúncios da redatorial. Outros exemplos de companhias que mantêm linhas não lucrativas, ou que continuam a servir territórios e clientes cuja contribuição para os lucros é menor que seu custo, simplesmente porque ninguém tem tempo de se preocupar com cifras, quando há coisas mais fascinantes para fazer.

E particularmente interessante notar que a atitude quantitativa pode ser de grande ajuda nas relações humanas do administrador. A objetividade dos números, mais que a emoção subjetiva, é uma maneira pela qual o indivíduo pode ser entendido e influenciado por outros. Isto tem sido ressaltado pelos cientistas sociais e parece ajustar-se aos fatos do mundo dos negócios, como se evidencia, por exemplo, pela ênfase da "General Motors" sôbre "a autoridade dos fatos" em contraste com a "autoridade de comando".

Diversamente do que ocorre com a mentalidade científica, a mentalidade administrativa tem que operar seletivamente com os números. A beleza e a precisão da mensuração podem ser admiradas sòmente até um certo ponto. Caso contrário aquêle que toma decisóes pode rotardar 
as coisas enquanto o paciente morre, perde-se a guerra, ou a firma deixa passar sua oportunidade.

As organizações de negócios podem precisar de pessoas que são profundas, zelosamente interessadas em quantificação, mas aquêles que recebem fatos quantitativos e têm que incorporá-los a ações decisórias, em tempo limitado, não deveriam possuir tal temperamento em grau muito elevado. Talvez a predisposição modificada para o administrador pudesse ser qualquer coisa como: "tentar, paciente e criativamente provar o resultado de sua decisão, pela procura de variáveis que possam ser mensuradas, mas não se deixar levar pelos sistemas matemáticos, a ponto de adiar ou evitar a decisão, quando a ação é necessária".

A propósito, temos aqui uma diferença interessante entre a mentalidade administrativa e a da maioria dos grupos profissionais. Alguns setores da organização podem estar tão fortemente entregues às técnicas quantitativas como qualquer cientista, e o próprio administrador que formula diretrizes pode participar vez ou outra de tais projetos; mas, quando está tomando decisões como um membro da alta administração, deve resistir vigorosamente à tentação de se submeter, de maneira estrita, a qualquer uma das várias posições setoriais.

Êsse é um problema geralmente insignificante para cientistas, advogados, médicos etc., que trabalham em grupos homogêneos. Todavia a heterogeneidade de uma organização empresarial requer do administrador um julgamento preciso e grande disciplina mental. Tal atitude, além de não impedir sua paridade com outras profissões, poderá ser ainda de grande valia para justificar o status profissional do administrador.

\section{ATRIBUTOS LÓGICOS}

Se bem que a limitação ao factual entre os homens de ciência possa parecer uma deformação, a maior parte dos cientistas reconhece a necessidade de uma delicada inte- 
ração e equilíbrio entre experimentos e observação, de um ladg, e especulação e raciocínio, do outro. O cientista especulará e teorizará nos mesmos têrmos físicos e matemáticos com que observa e prova, mas com abordagens diversas.

\section{Atitude Teórica}

O primeiro atributo da inteligência dedutiva é a ciência na similaridade e na harmonia dos acontecimentos através dos tempos. Concomitantemente surge um interêsse em descobrir conceitos que classifiquem êsses acontecimentos dentro de um mesmo significado e em inferir leis que governam o que acontece a um conceito quando um outro se transforma.

Essa é a atitude teórica, e apesar de na mentalidade popular estar mais freqüentemente associada à ciência, é bastante usada nos negócios. Por exemplo, temos um conceito denominado "estcque" e outros como "ativo circulante", "passivo circulante", "indice de liquidez comum" e "empréstimos bancários". O administrador financeiro sabe que quando o estoque aumenta e é pago com empréstimos bancários, o índice de liquidez baixa, uma vez que o ativo e passivo circulante são igualmente aumentados. Pode deduzir dessa relação outros acontecimentos futuros, como os seguintes: quando o estoque é vendido e o caixa é usado para construção de um edifício, transforma-se o ativo circulante em ativo fixo, e o índice de liquidez diminui. Deduz então o que acontecerá às outras partes do negócio, quando o índice de liquidez cai. Como vemos, todo êsse raciocínio procede através de uma cadeia de causas e efeitos.

Há centenas de conceitos e relações dessa natureza nas funcões de finanças, vendas, pessoal, fabricação etc.. Assim sendo, os espíritos matemáticos e físico-dedutivos realmente grandes, são aquêles que têm uma predisposição peculiarmente forte dessa natureza. AlBERT EINSTEIN tornou isso bastante claro quando disse: "Acredito como SHOPENHAUER que um dos mais fortes motivos que leva 
o homem à arte e à ciência é a fuga da vida cotidiana, com sua dolorosa crueza e monotonia desesperançada, dos próprios desejos sempre mutáveis."

Em outras palavras, inventando novos conceitos, abstraindo-se dos problemas, acontecimentos e situações do mundo real que nos cerca, o cientista foge para o que é para êle um mundo mais agradável de teoria e razão.

Essa atitude especulativa é de grande valia para o profissional na "linha de fogo". Atravessando dificuldades complexas de dirigir uma emprêsa ou um exército, qualquer um estará perdido se não puder catalogar a confusão dos fatos ou problemas em uma forma de compreensão mais simplificada, de maneira que sua mente possa manejá-los. Ao invés de tomar as teorias de alguém como "fantasias", ou dizer apressadamente "dê-me fatos e não teorias", muitos homens de negócio têm considerado útil ponderar sôbre o "Modêlo" do pesquisador operacional da firma, as "leis" dos economistas para a economia, e as hipóteses dos cientistas sociais sôbre a relação entre moral, participação e descentralização.

Acredito que os líderes empresariais e as escolas de administração deveriam incentivar um tipo de treinamento, tanto em lógica como em semântica, que desenvolva o interêsse pela "formulação de teorias" e pela aplicação de quadros teóricos à prática empresarial.

Desejando, contudo, evitar que o administrador profissional permaneça mais tempo nas nuvens do que no mundo real, a atitude teórica terá de sofrer modificações. Talvez pudesse ser enunciada assim: o raciocínio e o pensamento, bem como o uso de teorias alheias poderão ser válidos para a prática profissional, desde que se mantenha uma desconfiança saudável e um desejo de abandonar os conceitos teóricos, se não se ajustarem a um problema específico.

4) Albert Einstein, Essays in Science, Nova Iorque: Philosophical Libnary, 1934, pág. 2. 
Predisposição para a Verdade

O segundo atributo lógico que é útil ao administrador pode ser denominado "predisposição para a verdade".

A atitude da lógica aristotélica é aquela que diz: "Devo definir meus têrmos de maneira precisa, e verificar cada afirmação antes de usá-la como premissa na discussão e elaboração de quaisquer conclusões." Os semânticos modernos que desenvolveram um método suplementar, declararam: "Só saberemos o que é a verdade quando cada palavra fôt verificada e a idéia das características abstratas que estabelecem uma conexão entre a palavra e o objeto que representa no mundo real fôr formada."

A qualidade e a exeqüibilidade das idéias de um administrador dependem da verdade e da precisão das premissas com as quais êle raciocina. Assim, o conceito de verdade não é tão obscuro quanto parece. Sôbre êle repousam as possibilidades de serem ou não efetivas as decisões do administrador.

Como os outros atributos da inteligência tomados da ciência e da lógica, essa atitude deve sofrer modificações para poder ser utilizada pelo administrador. Muitas vêzes, tem que tratar com conceitos vagos e não pode retirar-se para um claustro e reduzir seu problema à verdade fundamental. O lógico, deparando com um objeto ambíguo e incapaz de identificá-lo, pcde recusar-se a aceitá-lo.

Por outro lado, o administrador tem que considerar todo e qualquer conceito que possa ser fator para elucidação de seu problema. Essa atitude modificada com relação à verdade poderia ser expressa da seguinte maneira: "Devo ser tão preciso em raciocinar sôbre fatos e pesquisas, quanto o tempo me permita, e devo procurar premissas e conclusões que sejam verdadeiras, mas não devo afastar o problema porque algumas afirmações não são passíveis de definição precisa." O conceito de "moral", por exemplo, é suficientemente fluido para que possamos utilizá-lo antes que se proceda a uma exaustiva investigação sôbre sua natureza. 
Suponhamos que o presidente de uma pequena companhia em fase de crescimento depare com o problema de contratar mais pessoas e atribuir-lhes tarefas, as quais devem ser coordenadas de maneira a atingir os objetivos de seu florescente negócio. Ao prescrever um padrão de trabalho e de tomada de decisão, êle raciocina que deve criar departamentos para as várias operações (planejar e decidir sôbre pormenores de tarefas, explicar e esclarecer o trabalho, a avaliação de resultados, o recebimento de informações dos empregados para avaliação etc.). Ou decide-se pela contratação de assistentes ou, ainda, delega essas tarefas ao departamento em questão. Pode mais tarde perceber que a escolha de uma dessas alternativas poderá ser feita em função dos seguintes fatôres: necessidades humanas, rapidez necessária para decisão, coordenação necessária entre as partes do fluxo de trabalho etc..

Alguns autores deram alguma precisão ao significaldo dos têrmos acima usados: departamento, planejamento, assistentes etc.. Mas, semântica e outros especialistas obrigam o administrador a procurar e usar cuidadosamente têrmos mais precisos e fundamentais, que dariam uma realidade concreta, claramente definida, à espécie de descentralização, à autoridade do homem de assessoria, ao papel do departamento no quadro revisado da organização e assim por diante. Òbviamente isso seria um empreendimento muito importante e impraticável, especialmente nesse estágio do desenvolvimento da administração.

Em conclusão, a atitude modificada com relação à verdade levaria o administrador a realizar o melhor nos limites de sua capacidade e no período de tempo disponível, utilizando para tanto os têrmos que se tivessem provado como os mais úteis. Êle não poderia abandonar temporàriamente suas atividades a fim de elaborar modelos dedutivos, ou para buscar premissas diversas.

A fluidez de muitos têrmos e conceitos em administração mostra uma falha da inteligência administrativa que não encontra paralelo nas ciências e demais profissões, com possível exceção de certas áreas do Direito. A situação 
sugere que um dos objetivos mais importantes do ensino de administração seria aumentar tanto o nosso conhecimento experimental como o dedutivo, sôbre práticas e diretrizes administrativas, de modo que as palavras que usamos simbolizem a realidade, mais acuradamente do que agora.

Imagino, por exemplo, se membros das faculdades de administração não deveriam dispor de algum tempo, ou de mais tempo para construção de modelos, e para coletar fatos "reais" do mundo dos negócios. Como ambos os tipos de conhecimento tornam-se disponíveis através dos anos ao futuro administrador, o compromisso com a predisposição científica para a verdade se tornará menos pronunciada.

\section{Coerência}

Um terceiro atributo lógico do administrador é a versão modificada da atitude de "validez" da lógica formal. Nós já tratamos da "veracidalde" e de "falsidade" das proposições no raciocínio do administrador. Agora, perguntamos se os argumentos em seu mecanismo são válidos ou não - ou seja, se as premissas, como enunciadas, são coerentes entre si em vez de contraditórias - e se o enunciado das conclusões e decisões é coerente com o enunciado das premissas.

Um excelente exemplo de forma lógica na indústria é a maneira pela qual as decisões para ação são preparadas pelo conselho de diretores da "Standard Oil New Jersey". Os projetos são geralmente preparados sob forma de propostas, com enunciados apresentando os resultados positivos e negativos da ação. Essa é uma forma dedutiva e é o reverso de uma outra seqüência usada comumente - a forma clássica de argumento indutivo onde uma série de enunciados é construída com proposições de ordem cálda vez mais alta, baseadas em fatos, seguindo-se então uma conclusão.

As razões pelas quais o administrador deve manter coerência dentro de limites são semelhantes àquelas mencio- 
nadas em conexão com a atitude sôbre a verdade. Tanto a lógica como a semântica, como disciplinas do espírito, demandam reflexão larga e paciente, desligada das pressões rotineiras das decisões operacionais. $\mathbf{E}$ muito freqüentemente êsse tempo necessário simplesmente não existe.

A disciplina do espírito que o administrador necessita deve ser qualquer coisa parecida com isto: "E necessário raciocínio claro e preciso das premissas à conclusão, para que minhas decisões profissionais e ações propostas sejam praticáveis. Entretanto, não passo esperar descobrir leis científicas em tôdas as decisões através de argumentos estritamente válidos, e algumas vêzes será necessário substituir a precisão silogística de pensamento, por racionalidade no sentido amplo."

\section{Em Defesa da Modificação}

Muitas vêzes não é claro ao observador porque o homem de negócio é obrigado a modificar as atitudes lógicas tradicionais, da maneira como fazem. Por exemplo, se o administrador demorasse e insistisse em mais verdade e coerência, não poderia, afinal, poupar tempo? Pessoalmente, duvido. Deixe-me ilustrar.

No ano passado tomei parte em uma jornada programada para administradores de alto nível, tanto de emprêsas como de administração pública. U'm especialista em lógica, nacionalmente conhecido, estava discutindo as ciladas e enganos, que são comuns quando não se faz uso adequado da técnica silogística. Sua tese parecia ser uma exortação aos administradores para que usassem tal raciocínio.

No periodo de debates que se seguiu, o conferencista foi apanhado pela audiência, em dois erros graves em seu próprio modo de pensar, erros de "generalização", e pareceu bastante despreparado para defender sua posição.

A razão foi que êle não percebeu que, ficando em pé diante de um grupo, respondendo perguntas, transformara-se de um lógico e pensador em um homem de ação. Viu 
que era necessário agir, respondendo tão jeitosamente quanto possível, e agiu.

Se êle tivesse permanecido, antes e acima de tudo, apenas como um lógico, ao invés de tornar-se um lógico interessado em auxiliar o grupo de administradores, ter-se-ia negado a responder perguntas até que pudesse enunciá-las claramente. Abandonaria a tribuna por um perícto tão longo quanto necessário, e pensaria numa resposta adequada. No caso em pauta, êle tentou ser um pensador e um homem de ação ao mesmo tempo, daí seu problema.

A lição que se pode tirar dêsse episódio é clara. Se as decisões são formuladas superficialmente, com baixo grau de validez e verdade, o administrador consegue tomá-las no tempo requerido, porém, poderiam então ficar inaproveitáveis. Por outro lado, se insiste em níveis elevados de validez e verdade, de maneira que seja levado a deixar seu trabalho para longos períodos de elaborações mentais abstratas, deverá permanecer na tribuna e dizer "não sei" a tôdas as perguntas e, afinal, nunca iniciar qualquer ação. Existe um ponto intermediário, que é o único procedimento prático, mas, isso requer um nôvo conjunto de atributos totalmente diferentes.

\section{ATRIBUTOS DA AÇÃo}

Voltamo-nos agora para um grupo de atributos, centralizados na ação, que disciplinam o espírito administrativo. Quem está acostumado a pensar de maneira científica opõe-se imediatamente a êsses atributos e diz: "Elas não são intelectuais." Visto que essa concepção errônea é uma das que impedem, tanto os profissionais, como os professôres universitários, de ver a importância das qualidades centralizadas na ação, e de tentar desenvolvê-las conscientemente, torna-se necessário explicar porque são de natureza intelectual.

Qualquer crença ou predisposição que influencie o modo de pensar de uma pessoa, as sequiências implícitas nas 
elaborações mentais, ou a maneira pela qual ela ataca um problema, pode ser considerada como uma atitude intelectual. Êsse é um dos significados da frase "maneira disciplinada de pensamento". Um cientista tem um conjunto de predisposições ou crenças, um artista outro, o professor um terceiro, e assim por diante. $\mathrm{Na}$ discussão que se segue vamos focalizar um conjunto de atitudes que influenciam o modo como trabalha a inteligência centrada na ação e como tenta ser factual e racional. Veremos grandes variações entre a mentalidade administrativa e a científica, mas também importantes semelhanças nas tendências intelectuais dos administradores, advogados e médicos.

\section{O Desejo de Transformar Coisas}

Relembrando a afirmação de EINSTEIN, anteriormente citada, sôbre como o cientista e o artista tentam fugir do mundo da ação rotineira, podemos dizer que o profissional tem um desejo em parte oposto ao de empreender ações que apresentem resultados. $O$ advogado deseja ganhar causas, tanto quanto apresentar uma argumentação brilhante. $O$ cirurgião deseja curar as pessoas, e também conhecer anatomia. $\mathrm{O}$ arquiteto quer levantar edifícios, o engenheiro construir pontes, o general do exército vencer batalhas. $\mathrm{O}$ administrador deseja obter resultados.

Há várias maneiras pelas quais cs administradores foram observados para demonstrar êsse atributo. Alguns deixam posições confortáveis seguras e de alto nível em uma companhia bem organizada para aceitar uma posição numa companhia, que está em dificuldades, atrasada em relação aos seus concorrentes ou falida. Essas situações problemáticas, difíceis, podem ser vistas como um desafio. Da mesma forma, um administrador que tem prazer em dar atenção aos departamentos confusos de sua seção, pode estar mostrando essa qualidade. Ela aparece também, em plano mais modesto, no desejo de introduzir melhoramentos em uma situação já boa, ou no "desejo de fazer algo nôvo". Freqüentemente, isso conduz a inovações que revelam resultados imediatos - como comprova, por exem- 
plo, o registro da "Prudential Insurance Company", nos últimos anos.

$\mathrm{Na}$ verdade, o desejo de mudar coisas pode ser mais característico dos "caciques" do que dos "indios". Por exemplo, William H. Whyte JR. diria que o "homem de organização" não se sente muito a vontade partindo de experiência comprovada, e CHRIS ARGYRIs, que pessoas que partem saudàvelmente com vontade de crescer e produzir inovações, ao contrário, tendem a adaptar-se à organização, tornando-se apáticos e desinteressados da companhia e de seus objetivos ${ }^{6}$. Ambos são provàvelmente um exagêro, mas a advertência é legítima. Certamente, é a administração em todos os níveis que necessita de uma disposição para a ação, uma vez que pequenas melhorias nos processos e técnicas podem somar o equivalente a "grandes" inovações.

Êsse desejo de mudar as coisas no mundo real é talvez completamente diverso daquele do cientista puro, que quer ser básico, factual, lógico e contribuir para a verdade e validez do conhecimento. $O$ cientista pode, de fato, querer transformar as coisas mas, não se preocupa demasiadamente com o momento. Pode mesmo ser em um futuro bastante remoto. Por exemplo, ARThur Burns, ex-assessor do Presidente dos Estados Unidos, enunciou sua preferência por resultados a longo prazo alcançados através de idéias sofisticadas, em lugar dos resultados comuns obtidos pelo trabalho do economista profissional no Govêrno ?

\section{Ação Oportuna}

Os administradores de alto nível, além do desejo de transformar coisas no mundo real, deveriam ter uma predispo-

5) The Organisation Man, Nova Iorque: Simon and Schuster Inc., 1956.

6) Personality and Organisation: the Conflict Between the System and the Individual, Nova Iorque: Harper and Brothers, 1957; e The Organisation: What Makes it Healthy?, H. B. R., novembro/dezembro de 1958 , pág. 107.

7) An Economist in Government, Columbia University Forum, inverno dẹ 1957, pág. 4. 
sição para a ação oportuna. JoHN L. BURNS, presidente da "Rádio Corporation of America" (RCA) e doutor em física, colocou a atitude da seguinte maneira: "Prefiro ser presidente do que estar certo" - querendo simplesmente dizer que, quando oportunidade e presteza de decisão são necessárias, a verdade e a validez devem ficar em segundo plano.

Parece haver pelo menos duas maneiras pelas quais o administrador manifesta sua incapacidade para a ação oportuna :

1) Insistir num dilúvio de fatos sem que chegue a conclusão alguma. Exemplos são comuns na maioria das emprêsas, ainda que raramente lembrados. E interessante notar que a história militar está cheia de casos em que comandantes se recusaram agir porque queriam mais fatos. O general McClellaN, por exemplo, errou quando seguiu LEE para a Virgínia.

2) O administrador pode adiar a ação por longo tempo sob alegação de que "devemos esperar para ver". O que na verdade êle mostra é temor de introduzir uma modificação até que tenha todos os fatos em seu poder. Quando tiver todos, será provàvelmente um pouco tarde para se realizar muita coisa.

\section{Capacidade de Julgamento}

O têrmo "julgamento" tem causado muita confusão. Usualmente é descrito apenas em têrmos mais gerais. F. R. Collbohn, presidente da "Rand Corporation", por exemplo, disse recentemente: "O que é julgamento? Julgamento nada mais é que experiência." $\mathrm{Na}$ verdade, o julgamento baseia-se em grande parte na experiência, mas descrevê-lo de maneira tão simples não faz, na minha opinião, justiça ao têrmo. O papel do julgamento pode tornar-se mais significativo se a palavra fôr desmembrada e analisada.

Os administradores e todos os homens de ação têm, muitas vêzes, de tentar extrair significado de seus problemas e 
resolvê-los, sem fazer certas coisas que o cientista ou lógico faz em sua paciente procura da verdade e validez. Para cada um dos instrumentos científicos pelos quais os eruditos eliminam o risco de seu modo de pensar, há um julgamento ou risco correspondente, que o homem de ação tem de assumir muitas vêzes, se pretende conseguir resultados no mundo real. Essas várias formas de julgamento podem ser consideradas como: julgamento conceitual, julgamento de quantidade, julgamento de ponderação, julgamento global.

O julgamento conceitual resulta do fato de que o administrador não pode reduzir a conceitos fundamentais, nem pela ciência (experimentação e generalização), nem pela lógica, as idéias com as quais trabalha. $O$ físico lida com fôrças e massas, átomos e elétrons; o químico lida com átcmos e moléculas; e o anatomista com corpúsculos e células. Por outro lado, a administração de uma companhia como a "General Motors" tem que lidar com símbolos multifacetados tais como "serviço ao cliente", "linha de produto", "tarefeiros", "duplicação de esforços" etc., com o fito de organizar sua diretriz para uma única fôrça de vendas que vende uma linha de produtos aos consumidores.

O uso dessas variáveis imprecisas ou mal cuidadas em um problema é uma tentativa do espírito administrativo de criar grandes instrumentos de pensamento, a fim de incluir uma porção de outras variáveis menores. Se o problema pudesse ser desmembrado em variáveis fundamentais, o que é impossível, tornar-se-ia tão complexo que não poderia ser resolvido.

A natureza do julgamento de quantidade e do julgamento de ponderação já foi mencionada. A administração da "Du Pont" e da "General Motors" não podem dizer: "Se descentralizarmos $68 \mathrm{mil}$ decisões para as divisões, a moral subirá em 5 graus, a rapidez de decisão aumentará de 35 milhas por hora, ou o treinamento de administradores de baixo nível será acelerado à razão de 16 libras por minuto." Ao contrário, o espírito administrativo estima o custo de emprêgo de administradores gerais para a direção de di- 
visões dependentes, em segundo lugar considera o efeito da proposta sôbre a rapidez da decisão, o aumento de motivação etc. e, só então, procura decidir.

O julgamento global resulta do fato de que o administrador não pode eliminar todos os milhares de fatôres de um problema, reduzí-lo a dois ou três fatôres, e então, triunfalmente, dizer que o valor dessa ou daquela diretriz ou curso de ação pode ser provado.

Pcuco depois da guerra da Coréia, a "International Business Machine Corporation" (IBM), defrontou-se com um problema: se devia, inicialmente, produzir um pequeno ou grande número de computadores modêlo 650 . Se o presidente da "Companhia Thomas Watson" fôsse um cientista, ao invés de um administrador, poderia ter provado que "permanecendo constantes o custo de fabricação, o custo do capital investido, os métodos de venda e propaganda, o número de empregados da fábrica, o preço dos materiais, uma mudança de 180 na produção de computadores daria 5 milhões nas vendas". ${ }^{8}$ Mesmo que isso fôsse uma verdade triunfante e 180 computadores fôssem vendidos por 5 milhões, a descoberta seria quase inútil, se o custo de produção por unidade caísse, o número de empregadcs variasse e assim por diante.

Dessa maneira, o administrador tem que tentar lutar com os milhares de efeitos em cadeia, tanto internos como externos, quando toma uma decisão importante. Ao fazê-lo, corre um risco decisório de estar errado na avaliação das relações.

\section{Desconfiança da Ciência}

Um dos equilíbrios mais difíceis de se manter na mentalidade administrativa é aquêle entre o respeito pela teoria científica e a desconfiança sadia em relação a ela. Há nos negócios uma longa história de "modas" que vêm e vão.

8) Scientific Aids to Decision-making: a Perspective, American Management Associaticn, General Management series, n. 187, 1957, pág. 43 
Evidenciam que tanto a boa comc a má ciência são oferecidas aos homens de emprêsa e que a boa ciência pode ser usada, gerando eficiência, bem como ineficiência. Para indicar a série de possibilidades, listamos cs seguintes exemplos:

- Em 1850 aproximadamente, Jeremy Bentham tentou ajudar o Govêrno inglês a estabelecer políticas para diretriz do país, através dos seus "cálculos de felicidade". Seu objetivo era capacitar o Parlamento a escolher entre as diferentes leis, pela mensuração dos prazeres e aflições que cada uma infligiria à população.

- A administração científica de TAYLOR vem sendo abandonada por muitas companhias. No passado um grande número aplicou-a como fórmula absoluta para solucionar seus problemas.

- Pouco antes da Segunda Guerra Mundial, um consultor, Charles E. BedeauX, convenceu à administração de um grande número de emprêsas que o sistema Bedeaux, de administração salarial poderia equacionar esfôrço humano e "repouso" com tecnologia e produção. Entre as ccmpanhias que fazem uso de sua teoria estão: a "American Rolling Mills", "Campbell Soup", "Diamond Match", "General Electric", "Du Pont", "Eastman Kodak", "Swift", "Postum" e "Gocdrich"."

Hoje, muitos cientistas sociais e matemáticos competentes estão tentando ajudar os administradores a resolver problemas. Lemcs sôbre estudos que indicam que a produtividade pode ser aumentada se os empregados "participarem"; ou que o moral pode ser aumentado com menor autoridade e pressão por parte dos supervisores. Além disso, conheço uma companhia onde foi feito e publicado um estudo dêsse tipo e que atualmente crê que há "algo de errado" em tais fórmulas.

9) The New Yorker, 22 de setembro de 1945, pág. 30. 
Talvez a chave dêsses mal-entendidos, entre cientistas e profissionais, esteja o conceito de "sistema fechado" em contraposição ao conceito de "problema global".

Freqüentemente os cientistas sociais enfatizam que sua missão é ajudar o administrador a entender o seu problema, e não lhe dizer o que fazer ${ }^{10}$. Não estão física e mentalmente mais capacitados para dizer ao administrador o que fazer, do que o próprio administrador. Mas, os cientistas do comportamento podem ajudar a esclarecer as variáveis humanas, da mesma forma que o engenheiro, o contador, o pesquisador mercadológico e outros, isolam as variáveis ligadas à tecnologia, custos, consumidor, preferência e os numerosos fatôres que aparecem associados no quadro da tomada de decisão. O que estou dizendo é que tanto os cientistas como os administradores deveriam relutar em pensar que formulações científicas podem resolver os problemas de ação em tôda a sua complexidade. O administrador erra se se empolga pela "participação", "administração científica", ou pelo sistema Bedeaux e emprega-o como uma fórmula para um problema de ação. Os cientistas também erram se escrevem suas publicações de maneira a querer dizer que seus conhecimentos serão válidos em uma base ampla e geral, sem ajustes ou modificações no mundo da ação. Uma razão para uma suspeita saudável em relação à teoria é ser usualmente impossível ou impraticável quantificar as variáveis de uma decisão. Certamente, "moral" e, como muitos administradores não ignoram, mesmo o lucro não podem ser mensurados com precisão.

Em pesquisas avançadas efetuadas com computadores, nas formas econométricas mais sofisticadas e nos modelos de pesquisa operacional, o matemático em geral ou: $10^{\circ}$ ) seleciona sòmente algumas variáveis, que podem ser mensuradas e deixa as outras variáveis ao executivo para julgamento; $2 .^{\circ}$ ) inclui mais variáveis, mas pondera-as arbitràriamente, como é feito em alguns jogos de emprêsas,

10) Veja-se Oportunities for Persuasion, Edward C. Bursk, H. B. R., setembro/outubro de 1958, pág. 111. 
muito em voga atualmente; ou, $3^{\circ}$ ) procura e ataca só aquêles problemas que se prestam a um alto grau de quantificação. Em qualquer um dêsses três casos, tanto o cientista como o administrador poderiam entender-se melhor se avaliassem o uso adequado e a limitação da ciência quantitativa.

Não quero dizer que o administrador deva ter uma visão pessimista do progresso da ciência social e da pesquisa operacional. A identificação demorada, paciente, das variáveis fundamentais, sua quantificação e o ajustamento da teoria, levarão, através dos anos à melhor solução dos problemas, mas devemos ser pacientes e perceber que embora estejamos em movimento, há um longo caminho ainda à frente.

\section{Objetividade e Valôres}

O cientista luta, acima de tudo, por algo chamado "objetividade". Esta consiste na crença de que sua missão é o estudo paciente e desapaixonado do meio ambiente dos fatos básicos da natureza e da maneira pela qual os vários fatôres se influenciam mùtuamente. $O$ administrador profissional também procura objetividade, mas sob condições diferentes. Por exemplo, a procura da verdade factual e lógica não é o mais alto objetivo que o governa, quando a oportunidade e resultados da ação são também importantes. Aqui também, diversamente da maioria dos cientistas, êle está pronto a entrar arrojadamente em debates sôbre questões éticas a ter a pesquisa influenciada, paralisada e modificada por fatôres subjetivos.

Por que o administrador e o advogado se permitem ser mais influenciados por considerações morais e éticas do que os cientistas? A resposta, ao que me parece, não tem muito a ver nem com personalidades e tradição, nem com a dimensão do tempo em que êsses homens trabälham. $\mathrm{Na}$ maioria das profissões aquêles que as exercem defrontam-se imediatamente com os resultados de suas decisões; por isso são naturalmente impelidos a levar em conside- 
ração valôres morais e éticos, juntamente com fatos objetivos. A título de ilustração:

- O médico, acreditando no valor da vida humana, comserva o paciente vivo em meio aos sofrimentos.

- O advogado, acreditando no direito que tôdas as pessoas têm de ver seu caso apresentado e defendido, defende o criminoso.

- O administrador, acreditando na dignidade do indivíduo, pode abster-se de despedir um operário idoso.

Em contraste, os cientistas não têm de se defrontar com resultados imediatos. Sejam quais forem os frutos de suas pesquisas, só adquirem caráter bom ou mau, decorridos, às vêzes, muitos ancs. Aquêles que trabalharam com a teoria "quântica" e ccm a relatividade, não sabiam se a bomba atômica seria usada em Hiroshima, ou se as usinas de energia atômica seriam construídas para aquecer e iluminar os lares da humanidade.

Se o progresso da ciência chegasse a tal ponto que um cientista trabalhando no seu laboratório num dia visse os resultados dêsse trabalho aplicados à atividade cotidiana, já no dia seguinte, talvez êle também fôsse obrigado a incorporar valôres não racionais às suas pesquisas.

\section{CONCLUSÃO}

Uma melhor compreensão dos atributos da mentalidade administrativa deve estimular o ensino de administração e o treinamento dos administradores. Para o administrador no seu cargo, isso daria significado e nobreza de objetivo às tarefas de realizar coisas por intermédio de pessoas. $E$ ajudaria na cristalização de padrões com os quais os homens de negócio possam ser comparados.

Como uma pessoa poderá desenvolver as qualidades descritas neste artigo?

De maneira geral, parece-me que alguém se aproxima do que foi exposto quando pode: 
1) Familiarizar-se com o conhecimento substancial dispcnível e com as atitudes e predisposições específicas que distinguem o administrador bem sucedido.

2) Observar os erros que os administradores cometem quando não aplicam essas qualidades.

3) Experimentar por si próprio sucessos e fracassos em presença de seus colegas e superiores.

Como método formal de treinamento, a administração pode tirar exemplos dos cursos jurídicos.

No desenvolvimento dos atributos da mentalidade legal, os júris simulados e o estudo do precedente foram muito valiosos nas Faculdades de Direito. Igualmente, no treinamento da metalidade administrativa, o diálogo socrático, juntamente com hábil ensino da teoria, seriam úteis. $O$ estudo de casos é excelente, visto que expõe o administrador ou estudante aos três caminhos acima mencionados.

O tipo de exame oral, comumente usado para debate de teses nas escolas superiores, sugere uma espécie de discussão que pode forçar efetivamente o pensamento através do fluxo da ação, criando uma prevenção em relação aos erros, baseada nos fatos e na lógica. Finalmente, os jogos de emprêsa devem ser úteis no desenvolvimento de qualidades lógicas, empíricas, bem como qualidades de ação anteriormente discutidas ${ }^{11}$.

Naturalmente, não há nada tão coator, como o exemplo dos próprios líderes administrativos em ação. Quanto mais puderem demonstrar pessoalmente os atributos da mentalidade administrativa, e quanto mais puderem torná-los uma realidade viva, mais significativos serão os esforços de cada um para aumentar o cabedal de conhecimentos administrativos.

11) Veja-se Business Games - Play One!, G. R. AndLInGer, H. B. R., março/abril de 1958, pág. 15; What Can Business Game Do?, H. B. R., julho/agôsto de 1958, pág. 147. 